\title{
Influence of Cognitive-Perceptual Functions on the Visuo- Motor Reaction in the Kumite of Traditional Karate
}

\author{
Radek Kleibl* \\ Faculty of Physical Education, Palacky University Olomouc, Czechia
}

*Corresponding author: Radek Kleibl, Faculty of Physical Education, Palacky University Olomouc, Czech Republic, Czechia

\begin{abstract}
Traditional karate is a martial art that is based on the principle of self-defense. This philosophy is also reflected in its sports side. However, there are certain rules that restrict athletes. These restrictions are mainly for the protection of human health. The main limitation is that the matches are without contact. It is also forbidden to strike in the direction of the most vulnerable parts of the human body, such as the eyes, ears, back of the head, neck, joints on the limbs and genitals. Great emphasis is placed on cognitive-perceptual skills, where the competitor must perform a visually effective striking technique at a time when the opponent is not able to defend himself or would have destructive effects in a real strike. Each match is for one point only and the normal time of one match is 1.5 minutes. Matches are physically demanding, so in addition to cognitive-perceptual skills, the athlete must also be physically fit. Physical fitness allows him to maintain attention and the ability to make the right decisions throughout the match. The work describes what the possibilities of reacting to a stimulus are and what effect physical condition has on the right decision.
\end{abstract}

Keywords: Cognitive-Perceptual Skills; Traditional Karate; Timing of Motor Response; Physical Condition

\section{Introduction}

We know stories from the history of martial arts in which the old man was able to defeat a younger and visibly more physically fit opponent, or more opponents [1]. Then it turned out that he was a well-known martial arts teacher. Because these people hid their skills and did not show everyone how to learn this, martial arts became very mystified. There were secrets that people could not explain. Today, thanks to our knowledge of the human body, we know how to be the best at training so that we have effectively increase our strength potential and have be able to perform the best of ourselves. Thus, the mystique of martial arts was disappeared. Today, a lot of martial arts have also a sports side, where meet equally physically fit opponents who have many years of experience in the field. The result of a struggle is determined by physical abilities and cognitive-perceptual-motor skills. Therefore, in martial arts and sports is important to correctly detect the opponent's movements and thus predict what opponent be going to do. This skill allows competitors to attack at the right time or to dodge an opponent's attack. Studies, which focus on the cognitive- perceptual-motor skills of people who practice various martial arts for a long time, show that the reaction time spent dodging the attack is longer than the time required to carry out an attack. A study of karate [2] measured the reaction time required by experienced karate practitioners to perform various movements. The time delay was found to range from $150 \mathrm{~ms}$ to $250 \mathrm{~ms}$. In a study by [3], in which participants responded to karate

Attacks from video record, they examined the difference in reaction between experienced karateka (a practitioner of karate) and beginners. The results showed that the decision times of experienced karateka are higher than $400 \mathrm{~ms}$ and emphasize the requirement for receptive abilities in karate [4]. The authors further stated that experienced karateka are significantly more accurate than beginners when making the right decisions [4]. also confirmed better results of experienced karateka in predicting the direction of offensive movements during video stimuli than in beginners. Other studies also provide evidence of large and systematic differences between experienced and beginning athletes in specific sports measures in pattern recognition [5] and prediction [6], which 
persist when the primary function is indistinguishable between different skill groups [7-9]. Studies that reported some significant professional advantage in one or more general visual function measures, such differences usually accounted for only a very small portion of performance variance [10]. In summary, there is evidence to argue against the assumption of a direct relationship between primary visual function and measures of athletic performance, and as a result suggest that improving primary visual function is unlikely to automatically lead to superior athletic performance [11].

Performance in martial arts is influenced by various factors such as aerobic endurance [12-14] maximum strength, anaerobic capacity [15], body composition [16,17] and body proportions $[18,19]$. Equally crucial is the ability to orientate oneself in space, process visual information and make the right decisions at the stimulus of the opponent [20,24]. Therefore, important components of performance athletes in the match are response time, the total time interval including both premature response times (RT; time from stimulus onset to adequate response) [25] and movement times (MT; interval between onset of movement to completion of movement). Reaction time in martial arts can affect an athlete's ability to optimize performance, concentrate, and make appropriate decisions [26]. In martial arts and sports, especially in limb-dependent sports, the ability to react quickly (RT) and use appropriate movements (MT) (along with techniques, tactics, combat strategy and expectations from an opponent) is very important. For this reason, the key skills that determine performance and success include the ability to quickly process information about an opponent's movement, to respond quickly and correctly so that the movement response is as effective as possible.

\section{Movement Skills in Kumite of Traditional Karate}

Competitions of traditional karate are based on the art of selfdefense. One of the categories of these competitions is kumite. Kumite is synonymous with karate wrestling and consists of performing freely chosen defensive and offensive techniques against an opponent [27]. The scoring technique in kumite is an offensive technique that represents the final punch. In harmony with the idea that the final punch does not give second chance to opponent, in competitions of traditional karate are the individual matches for only one point. It is about a concept of final blow. This concept leads to that the movement actions are controlled in such a way as to attain a scoring point that can end the whole match. This leads to inadequate physical actions are minimized. In combination with other movement actions, the final blow is created by the force of the whole body towards the target [28], which makes full use of the body's movement possibilities, such as body movement, rotation or vibration, pendulum principle, and decrease or increase the centre of gravity of the body. The technique that meets the concept of the final blow involves a correct timing of the upper or lower limb action towards the unprotected place of the opponent's body and as near to the opponent's body as it could be possible by the competition rules $(5 \mathrm{~cm}$ hands or $10 \mathrm{~cm}$ feet from the opponent's body).

\section{Sensori-Motor and Psycho-Motor Demands in Kumite}

In kumite, the defender must respond to his opponent's offensive action. In accordance with the cognitive psychological theory of information processing [29] and specifically in accordance with this theory applied to sports, rather movement activities [30-34] must the defender in karate process visual position and movement information body or body segments of the opponent at first. Visual processing of information includes recording (detection), subsequent recognition (reconnaissance) of the stimulus. This is preceded by a visual search for information (eye movement) that is relevant for recognizing the situation in the environment. These visually perceptual processes, rather information processing, leads to anticipation of what is likely to occur (in other words event anticipation). The anticipation is aided by the use of preliminary visual signals (opponent's body language), which is acquired through sports practice [32]. This is followed by motor response selection and motion programming [30]. Previously studies have provided quite a lot of evidence that elite athletes differ from less advanced athletes in higher quality or capacity of visual processes such as more effective patterns of searching for visual information, actually patterns of eye movement [8-34] faster detection of relevant stimuli [5] and faster reconnaissance situations in the environment, also known as "reading game" [6]. This knowledge was reflected in the use of the term sports-specific visual skills [32]. They are functionally followed by anticipation, whose level has been found out elite athletes higher than less advanced athletes in same the sport and which is also considered sport-specific [5].

There was paid more attention to the research of adaptation of visual perceptual functions, or actually their visual perceptual skills and anticipation of individuals performing sports games than combat sports. [35] found that experienced kickboxers are more accurate in predicting the direction of their opponent's attack than to less experienced ones. Experienced kickboxers used more effective patterns of searching for visual information, which were characterized by different localization of eye fixations in the visual field, fewer fixations, but longer duration. With deliberate distribution of attention, experienced kickboxers tended to maintain direct vision on the head and around the central area of the opponent's body (chest). Peripheral vision was also able to obtain information about the movement of the opponent's hand or foot, initiating the attack [35]. Studies of karate practitioners [3] and taekwondo practitioners [36] confirmed that experienced individuals tended to maintain direct vision of the head and chest area, while beginners often changed their vision. Visual perception of relevant stimuli in the visual field leads to decisions about the 
movement response to the situation. This process is seen as visual perception-action coupling [37-40]. Kumite decision-making skills are subject to high demands on timeliness (speed) [41]. In accordance with current views on the control of human movement and the acquisition of movement patterns [40], sports-specific visual skills and anticipations mature through a long-term performance of a certain sports activity, more or less implicit learning mechanisms, but also through deliberate creating specific situations in training exercises, i.e. explicit learning.

\section{Timing and Tactics in Traditional Karate}

In order that you can effectively perform defensive and offensive movements, it is necessary to mentally control your opponent, through your stable emotions, strong intention and right body position. Stable control of the mental condition (self-control) can be obtained in regular training, which develops both the physical potential and the mental side of the human body. If we are able to physically and mentally empathize with the opponent, then we are able to properly respond to the opponent's attack [28].

An important moment for performing offensive technique is the correct recognition of the opportunity to its use. It is a moment when our opponent is inattentive, his attention is somehow weakened. This suggests to us that opponent's reaction time is slower and his connection of the mind to his body is disrupted. This condition of the opponent is called "KYO" in karate. We recognize two types of KYO - mental and physical. Mental KYO involves unstable emotions, the opponent does not control his mental energy and his attention is distracted. Physical KYO involves the loss of balance and also a time when the opponent's body is in motion and the opponent change from one position to another, so-called inter-movement [28]. Another key point for the correct timing of defensive or offensive action in karate is distance. There are three basic types of distances-the actual distance between opponents, the individual effective distance (the best distance to perform your technique) and the distance of the opponent (guess of the opponent's abilities, i.e. guess of opponent's effective distance). If a competitor right understands the possibilities of his own distance and the distance of his opponent, then the competitor is able to choose the correct tactics for a match with his opponent, or perform the best of his own offensive techniques, or dodge the opponent's attack [28].

In traditional karate are three basic concepts for determining the time of attack or defense. These concepts are denoted by Japanese terms, which represent both offensive and defensive movements. These are further subdivided into other terms, where they are more specified and accurately indicate the time of attack or defense:

1) KAKE-WAZA (attack to opponent without opponent's attack) - It is the moment when the opponent's mental or physical unpreparedness (KYO) is recognized and karateka performs attack at a time when the opponent is unable to mentally or physically react.

2) OJI-WAZA (response to the opponent's attack) - OJI-WAZA is further subdivided into:

- $\quad$ SEN (attack to opponent's attack) - In Japanese kendo are used the more accurate term "sen no sen". It means to feel what your opponent is going to do [42]. If we use the current term, so this is an event of anticipation where we predict what happens. This is an attack to opponent who wants or starts attacking. We know two ways:

- KAKE-NO-SEN (attack before opponent's physical movement) - We attack to opponent's intention for attack. The opponent prepares to attack and defender attacks when the opponent decides to attack. In there are experiences important which we get through long-term and regular training, in order that we are able to anticipate the time when an attack occurs. An inexperienced observer often has to be impression that the aggressor is a defender. Without experience, it is very difficult to differentiate between KAKE-WAZA and KAKE-NO-SEN. Both timings of attack are the best kind of defence, because the defender performs punch to completely relaxed opponent's body and the opponent is not able to respond to this situation by a dodge or by firm the whole body. By using this timing is possible for lighter defender neutralized the opponent, who is significantly heavier.

- $\quad$ TAI-NO-SEN (attack with opponent's physical movement) - In this timing attacks defender at the same time with the opponent's attack. The defender changes the direction of the opponent's attack at the beginning of the opponent's movement and his own punch is over at the same time when the opponent's attack movement starts.

- II.GO-NO-SEN (attack to the opponent's attack, or dodge the opponent's attack)-This timing is an attack or deflection at the moment when the opponent is already performing a movement action. We divide it into two ways:

- UKE-WAZA (blocking the opponent's attack) - The opponent has already started a movement action; which defender stop by counter-movement or change a direction of the opponent's movement action. After blocking or changing the direction of movement performs the defender a counterattack.

- $\quad$ AMASHI-WAZA (body displacement/dodge opponent's attack) - The opponent performs a movement action and the defender is not able to stop the opponent's attack or change direction this attack. Before the end of the opponent's punch, the defender dodges attack by moving himself backwards. After avoidance the opponent's punch, the defender returns with his own counterattack and at the same time the defender removes the attacking opponent's limb aside, so that the defender do not bump into opponent's limb with a return movement. 
3) SHIKAKE-WAZA (tactics, preparation of opponent)-By this term is meaning the quest, preparation, and timing of karateka's offensive or defensive movement action. We recognize three basic types of tactics and preparation movement action of offensive or defensive technique:

- SASOI-WAZA (bidding-provoking movements)-By performing movements karateka drives or try to make the opponent feel that this is the right moment for his attack. If karateka manages to provoke the opponent to attack, karateka responds with an offensive or counterattack movement action (see the options above).

- $\quad$ KUYUSHI-WAZA (movements disturbing the opponent's
balance)-These tactics and preparations of opponents comprise movement actions that disturbing the opponent's physical or mental balance, which can cause the opponent's physical or mental unpreparedness (KYO) for karateka's offensive movement action.

- $\quad$ RENZOKU-KOKEGI-WAZA (continuous attack)-These are movement actions that press for the opponent to constantly block offensive actions and thus karateka gets the opponent in a situation that causes his unpreparedness. Karate uses the opponent's unpreparedness to perform his own punch that will neutralize the opponent so that he is unable to continue the match.

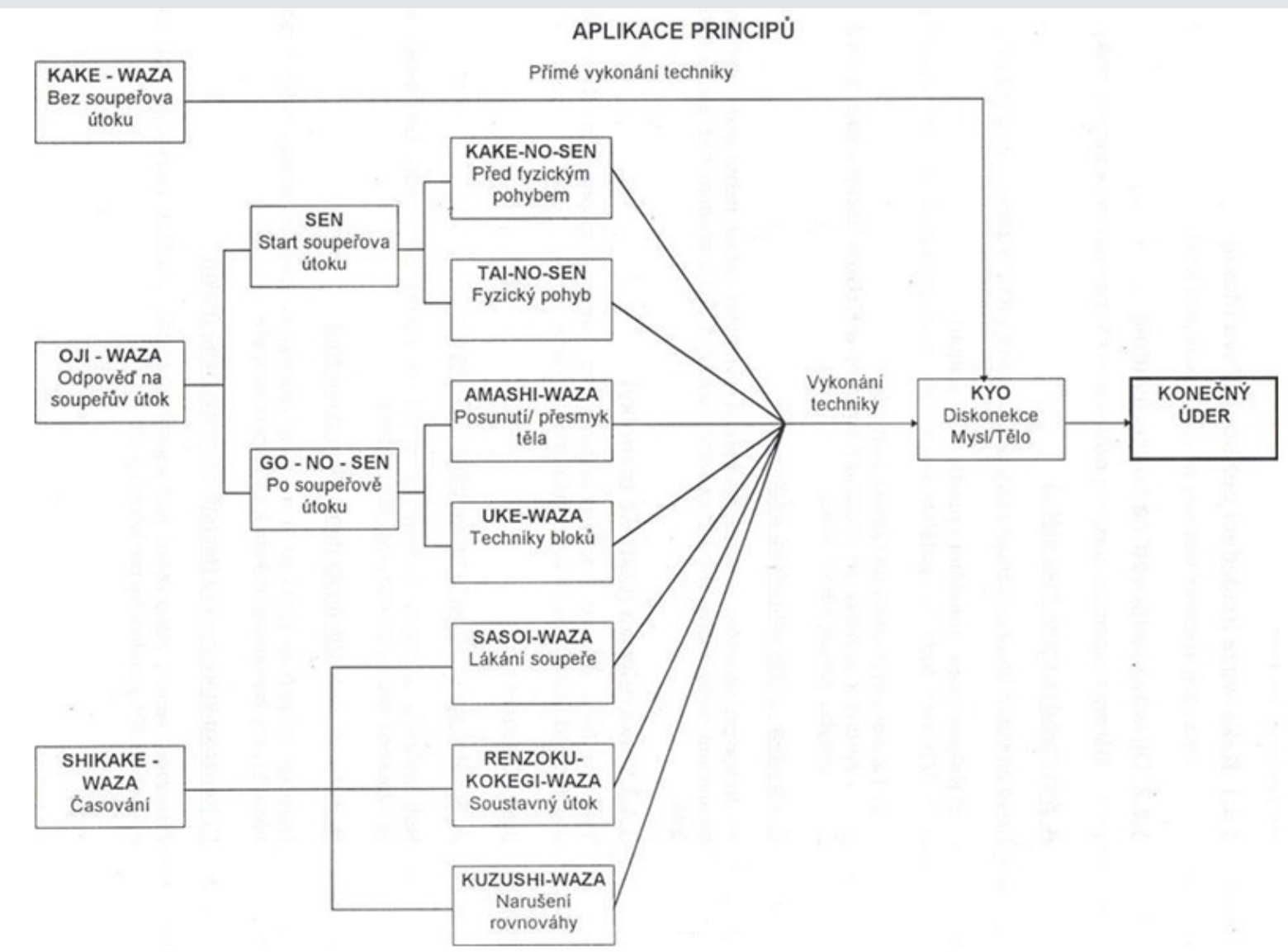

Figure 1: (Nishiyama, 1995), Classification of The Timing of Attack and Defence in Traditional Karate.

\section{Summary}

By the previous chapter follows that the teacher of traditional karate Hidetaka Nishiyama divided the cognitive-perceptual skills related to performing karate into groups that correspond to certain situations in a certain time sequence. These situations are based on the happening and behaviour of the opponent. The defender reacts to this by a movement action at a certain time. The most ideal defense is the time when the attacker is mentally already set to attack, and the defender prevents him from his attack. In such a situation, the attacker is the weakest, and the defender does not need as much power to neutralize him. Kumite (competition discipline) is based on the principles of self-defense and kumite in traditional karate should represent the ability to defend against a relatively stronger opponent by using karateka's own skill. In this discipline of traditional karate are no weight categories and, for reasons of health protection, kumite in traditional karate is non-contact, but punches or defensive actions must meet such movement skills that represent an effective punch or defense. In addition to the physical demands, there are high demands on the fast and correct processing of visual information. 
Successful athletic performance is affected by many physical and psychological factors, such as strength, endurance, strategy, or stress management. A study of MMA fighters [43], which examined the effect of acute fatigue on reaction times and reaction consistency of mixed martial arts fighters, stated that their results suggest that acute fatigue affects the overall performance and consistency of simple reaction time measures of MMA fighters. Several other previous studies have shown similarly significant effects of fatigue on overall response performance. The reaction times slow down with increasing load intensity $[44,46]$, as in the case of almost maximum or super maximum power [47-50]. We can state that sports performance of martial arts and combat sports is greatly influenced by physical factors, as well as visually perceptual functions, which are influenced by both physical and psychological factors - coping with stress, emotions. This finding is confirmed by the fact that there are big differences between advanced students and beginners of martial arts and combat sports. Early detection, subsequent recognition of stimuli and quick response processing is a component in martial arts that matures by a long-term repetition of movement activity, and lead to effective control of human movement and to acquire of movement patterns [40]. Specific visual skills and anticipations mature by regular repetition, which are mechanisms of implicit learning, but also by deliberately creating a specific situation in a training exercise, i.e. an explicit learning. Therefore, we know so many stories in the history of martial arts where a visually weaker person defeats a visually stronger opponent. There are studies that have examined the reaction time of athletes and non-athletes to optical stimuli. A study by [51] stated that the reaction time to the thrown ball of experienced cricket racers was below 200 [52] also identified reaction times to optical challenges: $200-300 \mathrm{~ms}$ for people who do not use any sports and 100-200 ms for experienced athletes. Other studies that have examined motor skill and the effect of

lower limb punch, such as study by [53] which compared.

Motor skill and its effect in roundhouse kick in the Muay Thai, Karate or Teakwonda styles. For example, this study detected that for Muay Thai style is a kick duration $1.02 \mathrm{~s}+/-0.15$, for Karate is a kick duration $1.29 \mathrm{~s}+/-0.28$, and for Taekwondo is a kick duration $1.54 \mathrm{~s}+/-0.52$. During the tutorial how to work with the Vicon MS camera system (Vicon Motion systems, Oxford, UK), which allows spatial (3D) kinematic analysis of motion, and how to correctly position the scan points so that the system can correctly record movement data of the attacking and defending limbs, for the research project "Visual stroboscopic training in karate: effects on motor reaction and attention", was determined the length of movement of the attacking front arm around $0.546 \mathrm{~s}$. If we take into account the results of studies $[51,52]$, which state that the react of experienced athletes to optical challenges (thrown ball) is 100 to $200 \mathrm{~ms}$, or the results of the study [2] which measured the reaction time for performing various movements of experienced karate practitioners in the range of $150 \mathrm{~ms}$ to $250 \mathrm{~ms}$, and consequently, we take into account the times required to punch the upper limb, which is about $546 \mathrm{~ms}$, and to punch the lower limb, which is about $900 \mathrm{~ms}$, we ascertain that defender have not much time for the defender's defensive movement and subsequent counterattack. Each movement action begins with an action that evokes a reaction and the movement itself [54]. The action is triggered by the leverage of an internal force (system of structures: organs, bones, muscles, tendons, ligaments, cartilage and other tissues) in contact with an external solid body - a floor. At the end of the movement, the muscles brake and contract, which stops the movement of the body, and the force, created by the movement, continues by inertia further in the direction of movement. The most effective punch is into a body that is in motion. The punch into the body that is strengthened and ready to attack has not any effect on creating such a destruction as would stop the attacking opponent.

In traditional karate competitions in the Kumite discipline, the visual processing of information, which includes the detection (recording), subsequent recognition (reconnaissance) of a stimulus and the correct choice of motor response with motion programming [30], is a very important factor influencing execution of a decisive and final strike. The visual processing of information, which includes the detection (recording), subsequent recognition (reconnaissance) of a stimulus and the correct choice of motor response with programming motion [30], is a very important factor influencing a performing of a deciding and final blow in competitions of traditional karate in the kumite discipline. This is preceded by a visual information search (more exactly eye movement) that allows relevant recognition of the situation in the surroundings. This visually perceptual process, rather information processing, leads to anticipation of what is likely to occur (event anticipation). Anticipation is aided by the use of preliminary visual signals (the opponent's body language), which are acquired through sports practice [32]. The Japanese named these skills KAKE-WAZA, OJIWAZA and SHIKAKE-VAZA. Each skill indicates a different situation and time that can occur in a struggle. All of these situations are the visual processing of information.

\section{References}

1. Svoboda S, Kopecký M, Hulinský P, Musil O, Rajchert J, et al. (2012) Encyclopedia of martial arts and sports. Prague: Mladá fronta.

2. Wilk SR, McNair RE, Feld MS (1983) The physics of karate. American Journal of Physics p. 51: 783-790.

3. Williams AM, Elliott D (1999) Anxiety and visual search strategy in karate. Journal of Sport and Exercise Psychology 21(4): 362-375.

4. Mori S, Ohtani Y, Imanaka K (2002) Reaction times and anticipatory skills of karate athletes. Human Movement Science 21(2): 213-230.

5. Allard F, Graham S, Paarsalu ME (1980) Perception in sport: Basketball. Journal of Sport Psychology 2(1): 14-21. 
6. Abernethy B, Russell DG (1987) The relationship between expertise and visual search strategy in a racquet sport. Human Movement Science 6(4): 283-319.

7. Starkes JL (1987) Skill in field hockey: The nature of the cognitive advantage. Journal of Sport Psychology, 9(2): 146-160.

8. Zaciorskij VM (1971) Theory and practice of physical culture -The physical characteristics of the athlete. Sportverlag Berlin p.55.

9. Abernethy B, Neal RJ, Koning PV (1994) Visualperceptual and cognitive differences between expert, intermediate, and novice snooker players Applied Cognitive Psychology 8(3):185-211.

10. Allard F, Graham S, Paarsalu ME (1980) Perception in sport: Basketball. Journal of Sport Psychology 2(1): 14-21.

11. Abernethy B, Wood JM (2001) Do generalized visual training programmes for sport really work? An experimental investigation. Journal of Sports Sciences 19(3): 203-222.

12. Bourgeaud P, Abernethy B (1987) Skilled perception in volleyball defense. Journal of Sport Psychology 9(4): 400-406.

13. Radovanovic D, Bratic M, Nurkic M, Stankovic N (2011) Recovery of dynamic lung function in elite judoists after short-term high intensity exercise. Arch Budo 7(1): 21-26.

14. Helsen W, Pauwels JM (1993) The relationship between expertise and visual information processing in sport. In Cognitive Issues in Motor Expertise (edited by J. Starkes and F. Allard) 102: 109-134.

15. International traditional karate federation, 2009. Competition rules.

16. Boileau RA, Lohman TG (1977) The measurement of human physique and its effect on physical performance. Orthop Clin N Am 8(3): 563-581.

17. Braswell MT, Szymanski DJ, Szymanski JM, Dixon EE, Gilliam ST, et al (2010) Physiological differences in mixed martial artist and traditional martial artists. A pilot study. J Strength Cond Res 24: 1.

18. Kirk C (2018) Does anthropometry influence technical factors in competitive mixed martial arts? Hum Movement 19(2): 46-59.

19. Kirk C (2016) Age and anthropometric variables and success in mixed martial arts. FACTA UNIVERSITATIS Series Physical Education and Sport 1:1-9.

20. Vicon MS (Vicon Motion systems, Oxford, Great Britain) (2010), Sophisticated diagnostics of human movement, reg. Number: CZ.1.07 2.3.00 / 09.0209, Faculty of Physical Education, Palacky University in Olomouc.

21. Gierczuk D, Bujak Z, Rowiński J, Dmitriyev A (2012) Selected coordination motor abilities in elite wrestlers and taekwon-do competitors. Polish J Sport Tour 19(4): 230-234

22. (2002) Physiological profiles of elite senior wrestlers. Sport Med. 32 225-233.

23. Mirzaei B, Curby DG, Barbas I, Lotfi N (2011) Anthropometric and Physical Fitness Traits of Four-Time World Greco-Roman Wrestling Champion in Relation to National Norms. A Case Study. J Hum Sport Exerc 6(2): 406-413.

24. Whitley JD, Montano L (1992) Relation between reaction time and movement time in college wrestlers. Percept Mot Skills 74(1): 171-176.

25. Balkó S, Borysiuk Z, Šimonek J (2016) the influence of different performance level offFencers on simple and choice reaction time. Rev Bras Cineantropom Hum. 18: 391-400.

26. Malhotra V, Goel N, Ushadhar U, Tripathi Y, Garg R (2015) Exercise and reaction times. J Evol Med Dent Sci 4: 4277-4281.

27. Imamura H, Yoshimura Y, Nishimura S, Nakazawa AT, Teshima K, et al. (2002) Physiological responses during and following karate training in women. J Sports Med Phys Fitness 42(4): 431-437.
28. Nishiyama H, 1995 Coach's manual. Los Angeles, CA: ITKF.

29. Sternberg R (2002) Kognitivní psychologie. 1 vydání. Praha: Portál.

30. Schmidt RA, Lee TD, Winstein CJ, Wulf G, Zelaznik HN (2018) Motor control and learning: A behavioral emphasis. Leeds: Human Kinetics.

31. Starkes, JL, Ericsson A (2003) Expert Performance in Sports. Leeds: Human Kinetics.

32. Williams, AM, Davids K, Williams JG (1999) Visual perception and action in sport. London: E \& FN Spon.

33. Williams AM, Davids K, Burwitz L, Williams JG (1994) Visual search strategies of experienced and inexperienced soccer players. Research Quarterly for Sport and Exercise 65(2): 127-135.

34. Sternberg R (2002) Kognitivní psychologie. 1 vydání. Praha: Portál

35. Ripoll H, Kerlirzin Y, Stein JF, Reine B (1995) Analysis of information processing, decision, making, and visual strategies in complex problem solving sport situations. Human Movement Science, 14(3): 325-349.

36. Lee J, Kim S, Younghoon S (2010) Visual search patterns and reaction movement in taekwondo according to expertise. Poster session presented at the meeting of NASPSPA, Tucson, Arizona.

37. Cullen KE (2016). Handbook of clinical neurology. Elsevier p. 137: 17-40.

38. Klostermann A, Panchuk D, Farrow D (2018) Perception-action coupling in complex game play: Exploring the quiet eye in contested basketball jump shots. Journal of Sports Sciences 36(9): 1054-1060.

39. Ledberg A, Bressler SL, Ding M, Coppola R, Nakamura R, et al. (2007) Large-scale visuomotor integration in the cerebral cortex. Cerebral Cortex 17(1): 44-62.

40. Prinz W, Beisert M, Herwig A (Eds) (2013) Action science. Cambridge, Massachusetts: The MIT Press pp. 462.

41. Fontani G, Lodi L, Felici A, MiglioriniI S, Corradeschi F (2006) Attention in athletes of high and low experience engaged in different open skill sports. Perceptual and Motor Skills 102(3): 791-805.

42. Imafuji H (ED) (2016) Kendo Terminology: Sen “Sen no sen” “Sen sen no sen" "Go no sen".

43. Pavelka R, Třebický Vít, Třebická Fialová J, Zdobinsky A, Coufalová K, et al. (2020) Havlíček J,Tufano JJ (2020) Acute fatigue affects reaction times and reaction consistency in Mixed Martial Arts fighters. PLoS ONE 15(1): e0227675.

44.Zwierko T, Lesiakowski P (2014) Visuomotor processing after progressively increased physical exercise. Cent Eur J Sport Sci Med 5(1): 27-34.

45. Sant'Ana J, Franchini E, da Silva V, Diefenthaeler F (2017) Effect of fatigue on reaction time, response time, performance time, and kick impact in taekwondo roundhouse kick. Sport Biomech 16(1): 201-209.

46. Hamze Sabzi A (2012) The effect of different fatigue protocols on choice reaction time. Middle-East J Sci Res 12(8): 1092-1096.

47. Gierczuk D, Lyakh V, Sadowski J, Bujak Z (2017) Speed of reaction and fighting effectiveness in elite grecoroman wrestlers. Percept Mot Skills 124(1): 200-213.

48. Garg M, Lata H, Walia L, Goyal O (2013) Effect of aerobic exercise on auditory and visual reaction times: a prospective study. Indian J Physiol Pharmacol 57(2): 138-145.

49. Gierczuk D, Bujak Z, Cieśliński I, Lyakh V, Sadowski J, et al. (2018) Response time and effectiveness in elite grecoroman wrestlers under simulated fight conditions. J Strength Cond Res 32(12): 3433-3440.

50. Sabzi AH (2012) The Effect of different fatigue protocols on choice reaction time. Middle-East J Sci Res 12(8): 1092-1096. 
51. Müller S, Abernethy B (2006) Batting with occluded vision: An in situ examination of the information pick-up and interceptive skills of highand low-skilled cricket batsmen. Journal of Science and Medicine in Sport 9(6): 446-458.

52. La Bounty P, Campbell BI, Galvan E, Cooke M, Antonio J, et al. (2011) Strength and Conditioning considerations for mixed martial arts. Strength Cond J 33(1): 56-67.
53. Gavagan CJ, Sayers MGL A (2017) A biomechanical analysis of the roundhouse kicking technique of expert practitioners: A comparison between the martial arts disciplines of Muay Thai, Karate, and Taekwondo. Morgan E. Carlson, Genomics Institute of the Novartis Research Foundation, PLoS ONE 12(8): e0182645.

54. Jandačka D, Uhlář R (2014) Fundamentals of biomechanics of sport and physical exercise. Ostrava, University of Ostrava Ostrava pp. 18-20.
To Submit Your Article Click Here:

This work is licensed under Creative Commons Attribution 4.0 License

DOI: $10.32474 /$ OSMOAJ.2020.04.000189

$\begin{gathered}\text { Orthopedics and Sports Medicine } \\ \text { Open Access Journal }\end{gathered}$
Assets of Publishing with us
- Global archiving of articles
- Immediate, unrestricted online access
- Rigorous Peer Review Process
- Authors Retain Copyrights
Orthopedics And Sports Medicine:
Open Access Journal

